\title{
Squamous cell carcinoma of lower lip in very young brothers of xeroderma pigmentosa
}

\author{
Hemant A. Saraiya, Mukul Trivedi' ${ }^{1}$, Jayesh Patel' ${ }^{1}$, J. T. Jhala ${ }^{1}$ \\ Sushrut Plastic Surgery Research Center, Apollo Hospital, and ${ }^{1}$ Gujarat Cancer and Research Institute, Ahmedabad, India
}

Address for correspondence: Dr. Hemant A. Saraiya, 10, Avanti Apartments, Bhagvan Nagar No Tekro, Paldi, Ahmedabad - 380007 , Gujarat, India. E-mail: drhemantsaraiya@hotmail.com

\section{ABSTRACT}

A nine-year-old xeroderma pigmentosa (XP) child presented with a non-healing ulcer on the right side of the lower lip. On histological examination the lesion proved to be squamous cell carcinoma. Wide excision was done. The excision included lip, buccal mucosa with mucocutaneous junction and only the upper portion of the orbicularis oris muscle. The lip was reconstructed with superiorly based nasolabial flap. Recently, his younger brother, who is also suffering from XP developed squamous cell carcinoma of lower lip, and presented to us. Wide excision of the lesion was done. The defect was closed primarily. The patient and his brother both have been advised to protect themselves from UV radiation. Both are being kept under intense surveillance. Ten months of follow-up of the elder brother showed satisfactory, good-looking lip with no sign of recurrence at the local site or at the neck.

\section{KEY WORDS}

Lip carcinoma, nasolabial flap, xeroderma pigmentosa

eroderma pigmentosa $(X P)$ is a rare autosomal recessive disease found worldwide in all races with an equal sex incidence. The disease is characterized by photosensitivity, pigmentary changes in skin, premature skin aging, neoplasia and abnormal DNA repair. Pigmentary changes on the face, with drying of sun-exposed skin, begin in infancy or early childhood. Light-or dark-brown macules are associated with telangiectases, angiomas, small, white atrophic spots and later with keratoses and tumours. In a fully developed case the diagnosis is simple and unmistakable. Malignant changes in the form of squamous cell carcinoma ${ }^{[1]}$ and melanoma are very common in the eye. Malignant transformations like basal cell carcinoma, angiosarcoma and fibrosarcomas at other sites have also been noted. In most cases patient reach tumour stage before attaining the age of 20. ${ }^{[2]}$

\section{CASE REPORT}

A nine-year-old child reported with a non-healing ulcer on the right side of the lower lip. The patient was confirmed to have XP and was on regular follow-up. Biopsy was carried out and the lesion was found to be squamous cell carcinoma [Figure 1].

Clinically no lymph nodes were palpable in the neck area. Wide excision was carried out keeping $0.7 \mathrm{~cm}$ of safe margin all around. The excision included lip mucosa, skin and lip muscle [Figure 2].

The lip was reconstructed with superiorly based nasolabial flap.

The orbicularis oris could not be approximated. Histopathological examination confirmed squamous 


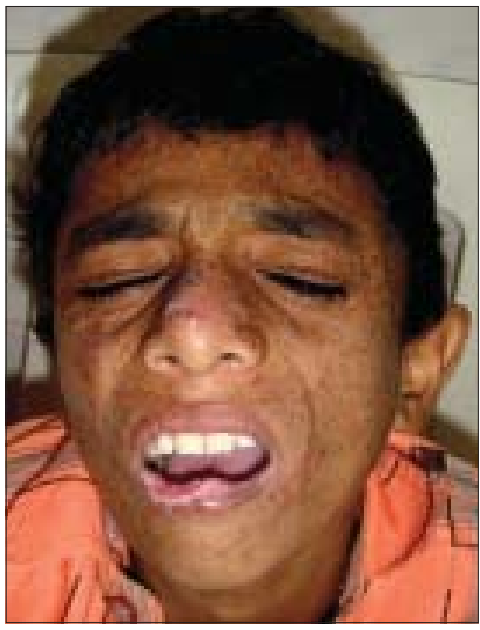

Figure 1: Non-healing ulcer on right side of lower lip

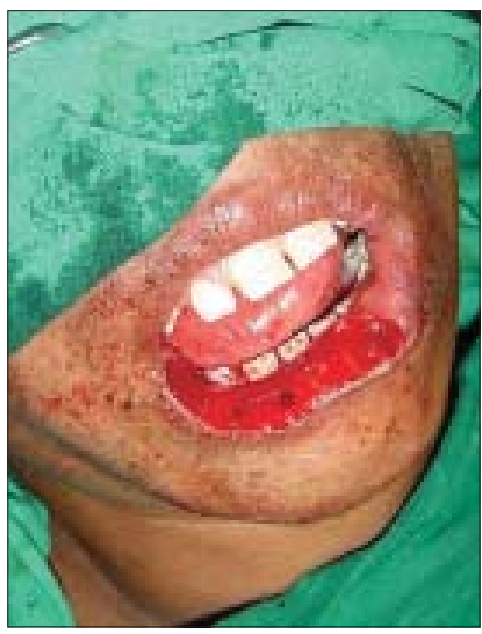

Figure 2: Wide excision

cell carcinoma. All margins and base of the specimens were free of tumour. No field changes were found in the specimen. Ten months of follow-up showed satisfactory, good-looking lip with no sign of recurrence either at the local site or at the neck. The preoperative twofinger mouth opening capacity of the patient remained unchanged after the operation [Figures 3,4].

Unfortunately, the eight-year-old younger brother of the victim was also affected by XP [Figure 5].

Recently, he too developed squamous cell carcinoma of lower lip. The lesion was excised keeping $0.7 \mathrm{~cm}$ of safe margin. The defect was closed primarily [Figures 6, 7-9].

Both brothers have been advised to use dark sunglasses, protective clothing and sun block agents to protect themselves from UV radiation.

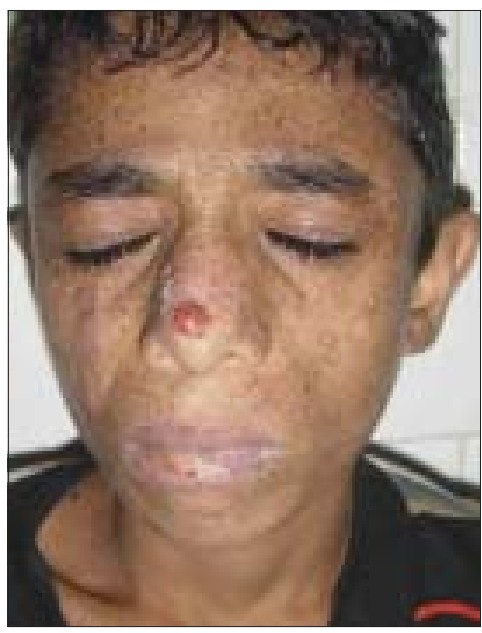

Figure 3: Lip reconstruction postoperative - close mouth

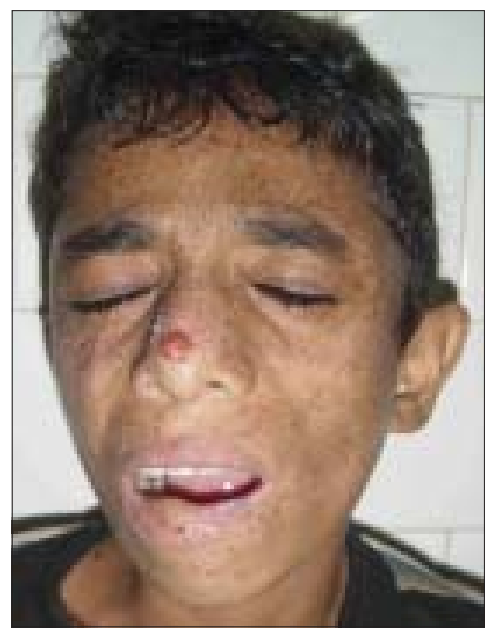

Figure 4: Lip reconstruction postoperative - open mouth

\section{DISCUSSION}

Lip reconstruction is always an interesting and challenging subject for any plastic surgeon. Primary closure, fan flap,,$^{[3]}$ Karapandzic flap, ${ }^{[3]}$ Abbe flap ${ }^{[3]}$ and nasolabial flaps, ${ }^{[3]}$ bilateral fan flaps ${ }^{[3]}$ and Webster's cheek advancement flaps $^{[3]}$ are a few of the reconstructive options available for vertical, full-thickness lower lip defects. Horizontal lip defects can be reconstructed either by bilateral pedicle mucosal advancement flap, ${ }^{[3]} \mathrm{V}-\mathrm{Y}$ mucosal advancement flap, ${ }^{[3]}$ nasolabial flaps or undersurface of tongue flap..$^{[3]}$ The V-Y advancement of lateral chin skin or submental artery island flaps are other good options for horizontal skin defects.

Vertical lip defects are comparatively easier to reconstruct than horizontal defects. Primary closure, reverse Abbe and Karapandzic flaps are good options for central lip 
defects. Lateral lip defect can be well reconstructed with fan flaps or modified fan flap.

Bilateral fan flaps ${ }^{[3]}$ and Webster's cheek advancement flaps ${ }^{[3]}$ are reserved for total lower lip reconstruction.

The bilateral pedicle mucosal advancement flap and $V-Y$ advancement of the mucosa is useful for mucosal replacement, small lip defects or lip shave defects. The under-surface of tongue flap provides a good amount of tissue but the tongue is difficult to immobilize postoperatively. Defects of skin and underlying musculature are more amenable to reconstruction using nasolabial flaps. The width of the nasolabial flap can also replace some part of the buccal mucosa which obviates the need for mucosal advancement flaps. It is easy to carry a superiorly based nasolabial flap to the lower lip and inferiorly based flap to the upper lip as there are less angulations, ectropion and other complications.

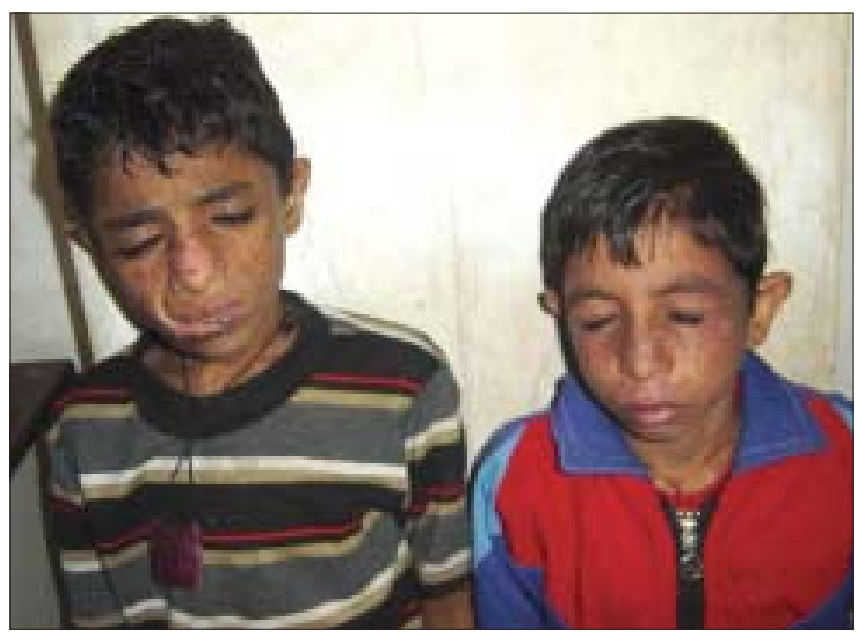

Figure 5: Affected brothers - December 2005

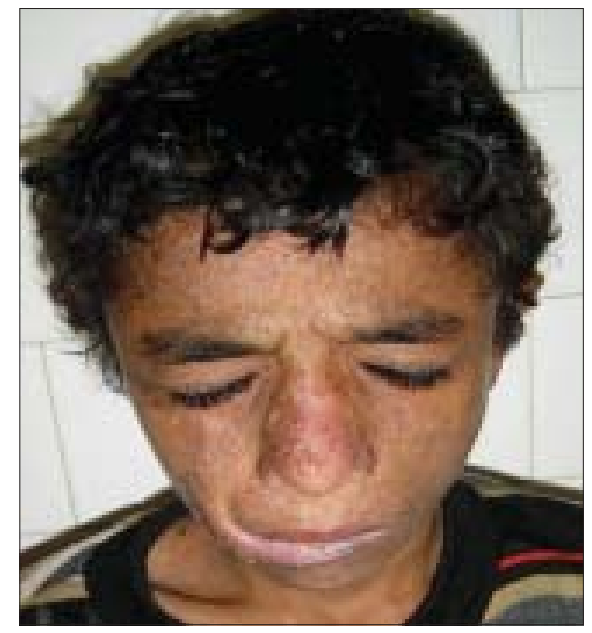

Figure 6: Lip reconstruction with right nasolabial flap
Before selecting a reconstruction modality, one also needs to know whether the tumour has arisen from the parakeratinising squamous epithelium of the lip mucosa(dry segment or the wet-dry junction) or the orthokeratinising

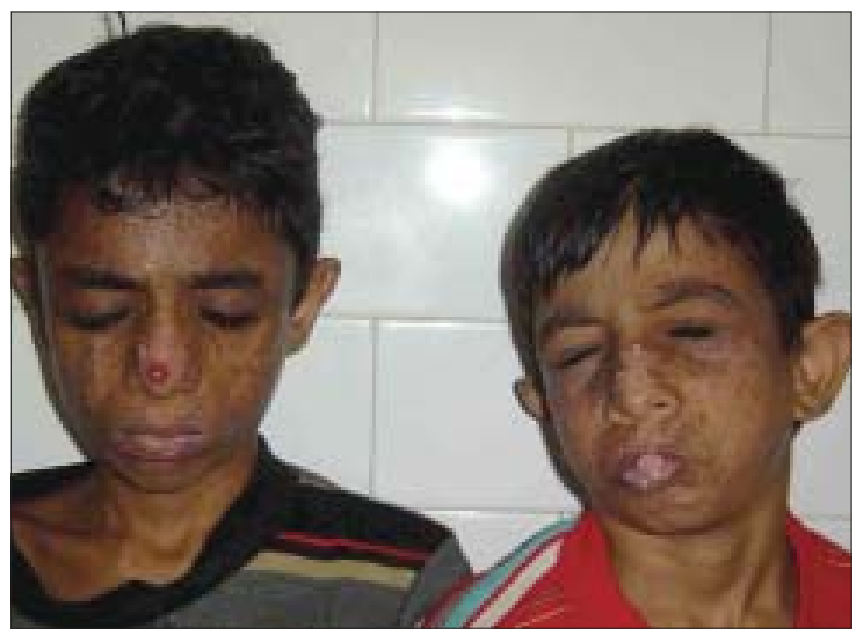

Figure 7: Squamous cell carcinoma of lower lip in younger brother - October 2006

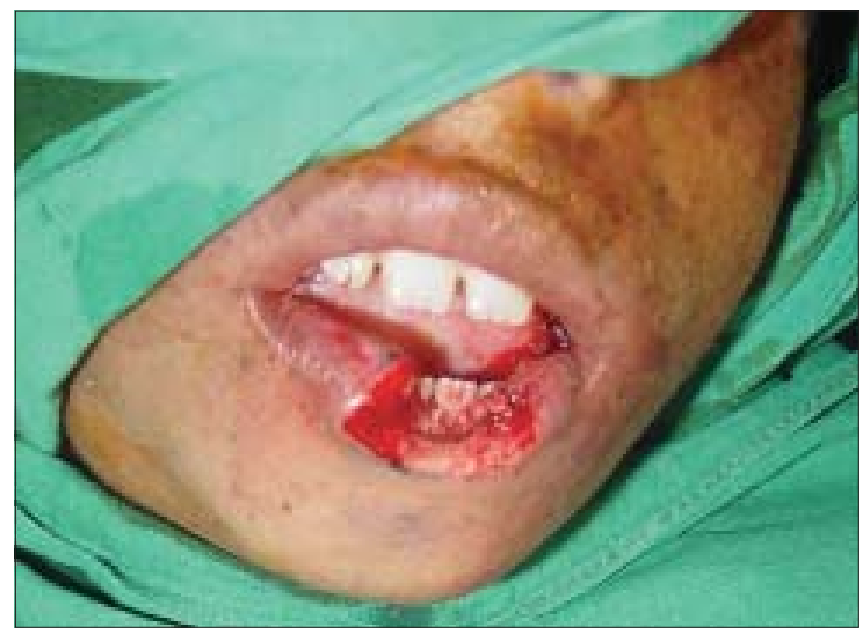

Figure 8: Wide excision

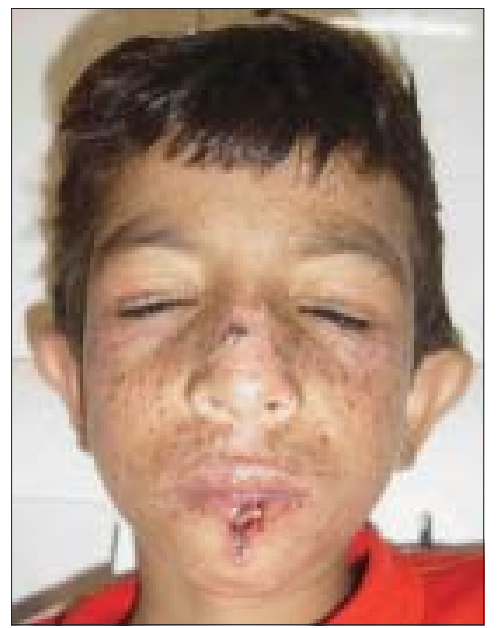

Figure 9: Postoperative photograph

Indian J Plast Surg July-December 2007 Vol 40 Issue 2 
skin of the external mucocutaneous junction. If the tumour is very aggressive on biopsy and arising from mucosa, it is worthwhile to consider the radical solution of replacing the entire lower lip mucosa with involved underlying tissue in a single cosmetic unit, rather than the conservative option of leaving a half and half situation of skin and mucosa.

In the above case the tumour was not exophytic and had eroded the lip. Even the histopathologist could not decide whether it arose from the skin or mucosa.

In this case the lip defect was partial and ho rizontal. Virtues of the nasolabial flap like reliability, ease of performance and adequate soft tissue replacement led us to utilize it in this case. Moreover, the point in favour of using skin to reconstruct the vermilion was that intraoral mucosa in an XP patient, freshly exposed to actinic stimulus, might be more sensitive to developing malignant change. ${ }^{[4]}$

Although rare, XP is unfortunatelya dreaded and incurable disease. The role of a reconstructive surgeon doesn't end with the completion of the reconstructive job.

Although definitive treatment of the disease may not be possible, the complications can certainly be prevented. Ultraviolet rays up to $320 \mathrm{~nm}$ are harmful and induce malignant change. Hence the patients have to be protected from sunlight. Eye protection with artificial tears and soft contact lenses is very useful. Different treatment modalities like topical 5-fluorouracil,, ${ }^{[5-7]}$ oral retinoids, $^{[5-8]}$ chemical peeling, dermabrasion ${ }^{[9]}$ and excision with grafting ${ }^{[10]}$ have been tried for premalignant or malignant lesions, ${ }^{[10]}$ more or less successfully.

Although patientsmay die of neurological complications, ${ }^{[11]}$ multiple metastases of squamous cell carcinoma and melanoma ${ }^{[12,13]}$ are the primary causes of death. Malignant changes in the eyes are very common and, obviously, the focus of a treating physician is more on the eyes, rather than on the other parts of the body. Such cases are an eyeopener which shows that malignant change can occur at any site of the body and at any age. The important thing is to clinically and histopathologically detect these changes very early and to treat them appropriately so that systemic metastasis can be prevented or at least delayed. but the association of squamous cell carcinoma of lip with Xeroderma pigmentosa has not been reported, at least not in very young brothers. An early diagnosis and treatment is essential and thereby a high index of clinical suspicion is required in patients with predisposing factors.

\section{ACKNOWLEDGMENT}

The authors are thankful to Dr. Mona Kelshikar for her help in preparing this manuscript.

\section{REFERENCES}

1. Bhutto AM, Shaikh A, Nonaka S. Incidence of xeroderma pigmentosum in Larkana, Pakistan: A 7-year study. Br J Dermatol 2005;152:545-51.

2. Harper Jl. Genetics and genodermatoses In: Champion $\mathrm{RH}$, Burton JL, Burns DA, Breathnach SM. The textbook of dermatology, $6^{\text {th }}$ ed. Blackwell Science CD Rom: New York; 1999. Chapter 12.

3. Jackson IT. Local flaps in head and neck reconstruction. $1^{\text {st }}$ ed. Mosby: St. Louis; 1985. Chapter 8.

4. Moretti A, Zingariello P, Chiri ZM, D'Agostino L, Croce A. Surgical treatment of malignant lip tumors: Personal experience. G Chir 2003;24:341-6

5. Berth-Jones J, Graham-Brown RA. Xeroderma pigmentosum variant: Response to etretinate. Br J Dermatol 1990;122:559-61

6. Kraemer KH, DiGiovanna JJ, Moshell AN, Tarone RE, Peck GL. Prevention of skin cancer in xeroderma pigmentosum with the use of oral isotretinoin. N Engl J Med 1988;318:1633-7.

7. Verret JL, Schnitzler L, Avenel M, et al. Etretinate and skin cancer prevention: A 6.5 year follow-up study. In: Saurat J, editor Retinoids: New Trends in Research and Therapy. Basel: Karger, 1985. p. 355-9.

8. Sauder DN. Editorial. J Cutan Med Surg 2000;4:1.

9. Nelson BR, Fader DJ, Gillard M, Baker SR, Johnson TM. The role of dermabrasion and chemical peels in the treatment of patients with xeroderma pigmentosum. J Am Acad Dermatol 1995;32:623-6

10. Gleason MC. Xeroderma pigmentosum-five-year arrest after total resurfacing of the face. Plast Reconstr Surg 1970;46:577-81.

11. English JS, Swerdlow AJ. The risk of malignant melanoma, internal malignancy and mortality in xeroderma pigmentosum patients. Br J Dermatol 1987;117:457-61.

12. Mehta C, Gupta CN, Krishnaswamy M. Malignant melanoma of conjunctiva with xeroderma pigmentosa: A case report. Indian J Ophthalmol 1996;44:165-6.

13. Goyal JL, Rao VA, Srinivasan R, Agrawal K.: Oculocutaneous manifestations in xeroderma pigmentosa. $\mathrm{Br} \mathrm{J}$ Ophthalmol 1994;78:295-7

14. Hertle RW, Durso F, Metzler JP, Varsa EW. Epibulbar squamous cell carcinomas in brothers with Xeroderma pigmentosa. J Pediatr Ophthalmol Strabismus 1991;28:350-3.

Source of Support: Nil, Conflict of Interest: None declared. 